\title{
Ensino Híbrido na Educação Superior: Análise da Produção Científica
}

\author{
Nei Muchuelo* \\ Almir Martins Vieira** \\ Rodrigo Ribeiro de Oliveira*** \\ Almir Martins Vieira*
}

\section{Resumo}

O ensino híbrido não é um termo novo nem um conceito revolucionário para as salas de aula. No entanto, a maneira como está sendo interpretado pode ser esperançoso ou prejudicial, dependendo de como esse ensino é implementado. As tecnologias devem ser empregadas para auxiliar os estudantes a se tornarem cidadãos capacitados, em vez de consumidores passivos. A metodologia deste estudo compreende uma pesquisa bibliográfica, com abordagem qualitativa, ainda que apresente alguns dados quantitativos para expressar o panorama dos artigos identificados. O objetivo foi identificar a produção científica sobre as publicações do ensino híbrido no Ensino Superior, realizando uma revisão sistemática referente ao período de 2005 a 2018, para o estudo foram selecionados 40 artigos, sendo 21 na área da Administração e 19 na área da Educação, tomando por base o Portal de Periódicos da Capes. Os resultados encontrados foram que esta tendência desconstrói os conceitos fixos que diferenciam

* Universidade Metodista de São Paulo (UMESP). Mestre em Administração pela Universidade Metodista de São Paulo (UMESP).

E-mail: muchuelo@bol.com.br.

** http://orcid.org/0000-0002-0523-3976. Universidade Presbiteriana Mackenzie. Doutor em Educação pela UNESP (2007); mestre e graduado em Administração pela Universidade Metodista de São Paulo (2001). Professor do Programa de Pós-Graduação em Administração da Universidade Presbiteriana Mackenzie. E-mail: almir.vieira@gmail.com .

*** Instituto Federal de Educação, Ciência e Tecnologia de São Paulo (IFSP). Professor do Instituto Federal de Educação, Ciência e Tecnologia de São Paulo (IFSP). Mestre em Administração pela Universidade Metodista de São Paulo (UMESP) e Doutor em Engenharia de Produção pela Universidade Metodista de Piracicaba (UNIMEP). E-mail: rodrigoribeirosp@hotmail.com . 
aulas presenciais das remotas, pois unifica a percepção do ensino e do aprendizado, independente do meio em que será transmitido. É fato que uma boa aula e docentes qualificados no ensino jamais substituirão aparelhos, tecnologias ou sistemas. No entanto, tornar o ensino mais atrativo e integrado aos hábitos dos estudantes, através do ensino híbrido, não só facilita o trabalho dos educadores envolvidos como torna os estudantes mais informados, críticos, protagonistas e interessados em todo o processo de aprendizagem.

Palavras-chave: ensino híbrido; educação superior; produção científica.

\section{Blended Learning and Higher Education: analysis of academic production}

\section{Abstract}

Blended Learning has held a place in educational change discussions over the last decades. Technological devices have been employed to help in the teaching-learning process, as well as in the education management. The purpose of this article is to identify the academic production about the blended learning theme, through a descriptive research, taking into account articles published and referred in the CAPES Indexing Database (Portal de Periódicos da CAPES). The period from 2005 to 2018 was considered in order to select the bibliographic data, collected form Business and Education knowledge fields. The research procedures result in 40 articles: 21 in the field of Administration and 19 in the field of Education. The results showed that this trend deconstructs the fixed concepts that differentiate face-to-face classes from virtual ones, because it unifies the perception of education and learning, regardless of the medium adopted during the classes, besides making students more informed and interested in the entire learning process.

Keywords: blended learning, higher education, academic production.

\section{Blended Learning en la Enseñanza Superior: análisis de la producción académica}

\section{Resumen}

El blended learning ha ocupado un lugar en las discusiones sobre el cambio educativo durante las últimas décadas.Se han empleado dispositivos tecnológicos para ayudar en el proceso de enseñanza-aprendizaje, así como en la gestión educativa. El propósito de este artículo es identificar 
la producción académica sobre el tema del blended learning, a través de una investigación descriptiva, teniendo en cuenta los artículos publicados y referidos en la base de datos de la CAPES (Portal de Periódicos da CAPES). Se consideró el período de 2005 a 2018 para seleccionar los datos bibliográficos, recopilados de los campos de conocimiento de Negocios y Educación. Los resultados arrojaron 40 artículos: con 21 en el campo de Negocios y 19 para el campo de Educación. Los resultados mostraron que esta tendencia deconstruye los conceptos fijos que diferencian las clases presenciales de las virtuales, porque unifica la percepción de educación y aprendizaje, independientemente del medio adoptado para las clases, además de hacer que los estudiantes estén más informados e interesados en todo el proceso de aprendizaje.

Palabras clave: blended learning, enseñanza superior, producción académica.

\section{Introdução}

A tecnologia e seus avanços estão promovendo mudanças na forma da utilização de produtos e serviços conhecidos como inovação disruptiva que, segundo Horn e Staker (2015), se caracterizam por provocar uma mudança no sistema atual, oferecendo novas opções, sem diminuir ou retirar daquele que já estava em funcionamento. $\mathrm{O}$ ambiente escolar progrediu de uma escola medieval, posteriormente adaptada para a época da Revolução Industrial, quando todos eram educados como uma linha de produção (GABRIEL, 2013; JARAUTA; IMBERNON, 2015).

Desde o século XVIII, estudiosos têm demonstrado interesse em mudar o processo educacional. O principal enfoque neste processo é a nova escola, para que o ensino seja um instrumento de reflexão, de transformação, colocando o estudante como centro do processo, tornando-o responsável pela construção do seu conhecimento (GADOT'TI, 1999). No século XXI, na Era da Informação e do Conhecimento, houve muitos avanços tecnológicos, mas o que ainda se observa, em sala de aula, são docentes com a ideia de que eles são a fonte do conhecimento dos estudantes, preocupados exclusivamente com os conteúdos (GABRIEL, 2013).

De acordo com Bacich e Moran (2018), o processo de evolução do ensino possui dois conceitos importantes: o ensino hí- 
brido e as metodologias ativas. O ensino híbrido é uma forma de aprendizado formal, na qual o estudante aprende parte no ambiente presencial (síncrono), parte por meio do ensino remoto (assíncrono), sendo ainda que esse aprendizado pode ser em qualquer lugar, utilizando qualquer um dos meios mais recentes de tecnologia, como: computadores, tablets, smartphones, entre outros. As metodologias ativas, por sua vez, colocam o estudante no centro do processo, procurando despertar sua reflexão, sua participação, enfim, seu envolvimento. Nesse contexto, o docente não mais "ensina" o estudante, ele é mediador, e todo o processo de ensino se baseia no ato do estudante descobrir, questionar e pesquisar, sob a orientação do docente (FIORAVANZO; VIEIRA; CLARO, 2016; BACICH; MORAN, 2018).

A aprendizagem tradicional é aquela em que o material é entregue ao estudante por meio de um docente, por meio de interações face a face. Por outro lado, o aprendizado remoto envolve o uso da internet para acessar material didático sem a presença física de um docente (GÜZER; CANER, 2014).

Segundo Chan e Leung (2016), acredita-se que os estudantes absorvam conhecimentos, adquiram prática e desenvolvam suas competências. A utilização de ferramentas tecnológicas é cada vez mais necessária para apoio ao trabalho docente. No método de aprendizagem tradicional, os docentes determinam o que os estudantes aprenderão e como seu desempenho será avaliado. Ainda, de acordo com os autores, essa didática proporciona aos estudantes menos liberdade e flexibilidade para aprender, dificultando o desenvolvimento da aprendizagem ao longo da vida e habilidades independentes de resposta aos problemas dos estudantes.

O ensino híbrido é um programa de educação formal, no qual um estudante aprende, pelo menos em parte, por meio do ensino remoto, com algum elemento de controle do estudante sobre o tempo, o lugar, o modo e/ou ritmo do estudo, e pelo menos em parte em uma localidade física supervisionada, fora de sua residência (CHRISTENSEN; HORN; STAKER, 2013, p.7). 
O resultado de toda a discussão sobre o tema é a tendência atual de "convergir aprendizagem tradicional e aprendizagem em ambientes virtuais de aprendizagem, rumo a uma coexistência harmoniosa entre o ensino presencial e remoto, em variadas proporções”, segundo afirmação de Romero (2010), que destaca ainda que, quanto maior for a combinação entre as modalidades, ou seja, à medida que cursos tradicionais passarem a utilizar mais recursos em ambientes virtuais de aprendizagem e cursos a distância incorporarem maior número de atividades presenciais, será complicado separá-las (ROMERO, 2010).

A tecnologia se tornou parte integrante dos ambientes educacionais. Os avanços tecnológicos alteraram, significativamente, as formas como os docentes ensinam e os estudantes aprendem. Além disso, os docentes vêm sentindo uma grande pressão para integrar a tecnologia em suas aulas. Eles têm que reavaliar suas práticas de ensino e, em vez de evitar, devem incorporar o uso da tecnologia, aplicando suas vantagens de modo a alcançar os objetivos de aprendizado. As oportunidades apresentadas pelas tecnologias em ensino são ilimitadas e sem fronteiras (JOHNSON et al., 2014; MENDONÇA NETO; VIEIRA; ANTUNES, 2018).

Dado esse contexto, o objetivo deste estudo foi identificar a produção científica sobre ensino híbrido no Ensino Superior, no Brasil, na forma de artigos científicos publicados em periódicos das áreas de Administração e Educação, tendo por base os textos indexados no Portal de Periódicos da Coordenação de Aperfeiçoamento de Pessoal de Nível Superior (CAPES).

\section{Fundamentação Teórica}

O ensino sempre combinou diversos espaços, tempos, públicos, atividades e metodologias. No ensino acontecem vários tipos de misturas, ensino híbrido de saberes e valores quando se integram várias áreas do conhecimento (no modelo disciplinar ou não), metodologias com desafios, atividades, projetos, games, grupais e individuais, colaborativos e personalizados (MORAN, 2015). 
Nesse cenário, ensino híbrido é um método pedagógico que integra os pontos fortes do ambiente de sala de aula presencial no mundo físico e as atividades de aprendizagem remota - não presencial - (RAZEP; ABEL, 2014; AL-ALWANI, 2014; PEERAER; VAN PETEGEM, 2015).

$\mathrm{O}$ aprendizado remoto fornece flexibilidade e acesso mais fácil ao conteúdo, em qualquer hora e em qualquer lugar (MEANS et al., 2013). No entanto, permanece muito controverso, uma vez que não se compara aos ambientes de sala de aula presencial (tradicionais), que incentivam a comunicação e melhoram as habilidades sociais (MEANS et al., 2013).

O ensino híbrido está ganhando popularidade em função de sua abordagem na combinação de ensino presencial e ensino remoto, facilitando a integração e possibilitando a aproximação entre diferentes espaços e ambientes. Parece se tratar de uma resposta para uma pedagogia transformadora e emancipatória (GÜZER; CANER, 2014), em busca de equilíbrio, preservando os métodos tradicionais de ensino, ao mesmo tempo em que se integram "tecnologias no processo de ensino e aprendizagem” (NAZARENKO, 2015).

Os mais jovens, nativos digitais, apresentam conjuntos distintos de comportamentos, que são produtivos para a aprendizagem, como a predileção pela velocidade, processamento não-linear e aprendizagem social, além de multitarefa (RIDEOUT; FOEHR; ROBERTS, 2010).

O uso de métodos alternativos ao tradicional de ensino está intimamente ligado à evolução tecnológica. Tentativas de se ensinar remotamente vêm acontecendo desde o fim do século XIX e início do século XX, principalmente, com o uso da correspondência e do rádio para se ensinar a distância (SHERRON; BOETTCHER, 1997).

Assim, apesar de já estar presente em diferentes contextos diários e de ser considerada importante no ensino, as inserções das tecnologias digitais nas Intuições de Ensino têm sido lentas. Nesse sentido, as metodologias de ensino ainda permanecem voltadas para um modelo tradicional. Nesse cenário, que permeia a cultura digital e tecnológica, se faz necessário que as Instituições de Ensino 
se posicionem diante de novos recursos, trazendo uma reflexão, em que a pauta seja alternar as estratégias de ensino, combinando a integração de recursos tecnológicos com formas tradicionais de aprendizagens (CHRISTENSEN et al., 2013).

O que a tecnologia traz hoje é a integração de todos os espaços e tempos. O ensinar e o aprender acontecem em uma interligação simbólica, profunda e constante entre os chamados mundo físico e digital. Não são dois mundos ou espaços, mas um espaço estendido, uma sala de aula ampliada, que se mescla, hibridiza constantemente (BACICH; TANZI NETO; TREVISANI, 2015).

Dessa forma, as tecnologias contribuem para algumas mudanças, inclusive, na parte pedagógica. As tecnologias tanto servem para reforçar uma visão tradicional, como contribuir com uma visão progressista do ensino (MORAN; MASET'TO; BEHRENS, 2007).

Outro aspecto importante, que deve ser levado em conta, diz respeito às variáveis que ampliam a compreensão relacionada às diferenças das diversas gerações que convivem na contemporaneidade e nos mesmos ambientes, além de outros fatores que implicam e interferem na formação de cada sujeito e influenciam ter mais ou menos facilidade para utilizar as ferramentas das mídias digitais sociais, tais como: cultura, família, educação, padrão econômico e localização geográfica. Da mesma forma, devem ser levados em conta também elementos como: acontecimentos sociais e culturais coletivos, sobretudo, os aspectos comportamentais mais fáceis de serem identificados (CALIPO, 2013).

Segundo Ferreira e Vieira (2013) e Bacich e Moran (2018), o papel do docente muda se tornando um articulador com capacidades de mediar, de analisar as necessidades e lacunas dos estudantes, se tornando um design de roteiros e atividades para aqueles que buscam o conhecimento. Bacich e Moran (2018) ainda ratificam que a metodologia ativa de ensino é centrada na aprendizagem pela experiência e no desenvolvimento do aprendiz. Para os autores, "nos últimos anos, tem havido uma ênfase em combinar metodologias ativas em contextos híbridos que unam as vantagens das metodologias indutivas e das dedutivas", e estas metodologias não são exclusivas do ensino híbrido. 
O aprendizado é um processo constante e que envolve os campos pessoal, profissional e social. Desde o nascimento o indivíduo aprende observando, testando, errando, experimentando. Aos poucos amplia e generaliza essas experiências em um processo indutivo, ao mesmo tempo que também aprende a partir de teorias que, depois, testa na vida real - processo dedutivo. Nas Instituições de Ensino, em geral, há o predomínio da aprendizagem pelo processo dedutivo, em que o docente transmite primeiro a teoria para que os estudantes a assimilem e tentem, posteriormente, enquadrá-la em algo concreto, que faça parte da vida. Trata-se de uma abordagem importante, porém cada vez mais se nota que a aprendizagem por questionamento e experimentação - processo indutivo - proporciona uma compreensão mais ampla e profunda, uma vez que traz ao estudante uma participação mais ativa em todo o processo (BACICH; MORAN, 2018).

Assim, Cruz e Bizelli (2014) argumentam que no atual panorama educativo da era digital, em que o conhecimento e a prática docente não são mais apenas atribuições específicas das Instituições de Ensino, o docente deve ampliar e não reduzir sua ação de agente da memória educativa, visto que nesse universo é papel do docente recuperar a origem e a memória do saber.

Os ambientes virtuais de aprendizagem, muito utilizados para a troca de informações, desenvolvimento da criatividade e a ampliação de conceitos são prova de como a tecnologia pode agregar valor à disseminação do conhecimento, favorecendo de forma significativa as atividades interativas (CRUZ; BIZELLI, 2014).

As tecnologias devem ser empregadas para ajudar os estudantes a se tornarem cidadãos capacitados, em vez de consumidores passivos. São necessárias práticas de inovação em todos os níveis educacionais (PEREIRA; VIEIRA; DAMIÃO, 2018), de forma a criar uma sociedade na qual as pessoas possam florescer em comunidades culturalmente ricas, informadas, democráticas, digitalmente conectadas e diversificadas, buscando alcançar um equilíbrio mais 
sutil, que combine as tecnologias digitais e a presença física de um docente atencioso e conhecedor (HORN; STAKER 2015).

\section{Procedimentos Metodológicos}

Este estudo assume abordagem qualitativa, com exploração documental de material, ainda que apresente alguns dados quantitativos para expressar o panorama dos artigos identificados. Assim, enfatiza-se, reforça-se e reitera-se que a utilização da pesquisa bibliográfica é preponderante para o acompanhamento e o alcance do objetivo do estudo de examinar a produção científica sobre o tema ensino híbrido. $\mathrm{O}$ teor qualitativo da proposta assumida reside no interesse interpretativo a respeito do conteúdo do material bibliográfico selecionado para esta investigação (ROMANOWSKI; ENS, 2006; VIEIRA, 2007; VIEIRA; RIVERA, 2012; TOMACHEVSKI; LEPCHAK, 2019).

Tomando por base o Portal de Periódicos da CAPES, foram obtidos 77 artigos publicados em periódicos tratando do tema no Brasil. Em seguida, foram excluídos 12 artigos por não pertencerem a periódicos das áreas de Administração e Educação, critério assumido para esta pesquisa, e 25 por não tratarem do tema no Ensino Superior.

A coleta de dados ocorreu mediante consulta ao site do Portal de Periódicos da CAPES, por meio da palavras-chave "ensino híbrido", na busca por assunto que contenha as palavras, em qualquer parte do artigo, e na busca avançada que contenha as palavras no tema, marcando os eventos de interesse, com vistas a encontrar os artigos que possuam o termo, ou seja, que tratam do tema como questão principal. Após, foi realizado um filtro dos artigos, com a leitura dos resumos, sendo escolhidos os trabalhos que discutiam os temas no âmbito do Ensino Superior.

Para o estudo, foram selecionados 40 artigos, 26 com as palavras em qualquer parte e 14 artigos com as palavras: ensino híbrido no assunto, sendo 21 na área da Administração e 19 em Educação, conforme a Tabela 1. 
Tabela 1. Periódicos e quantidade de artigos identificados

\begin{tabular}{|c|c|c|}
\hline PERIÓDICOS & ÁREA & OCORRÊNCIAS \\
\hline Acta Scientiarum. Education (UEM) & Educação & 1 \\
\hline $\begin{array}{l}\text { Administração: Ensino e Pesquisa } \\
\text { RAEP (ANGRAD) }\end{array}$ & Administração & 1 \\
\hline Cadernos EBAPE.BR (FGV) & Administração & 3 \\
\hline Ciência \& Educação (Unesp Bauru) Scielo & Educação & 1 \\
\hline Educação \& Sociedade (CEDES) Scielo & Educação & 1 \\
\hline Educação em Revista (UFMG) Scielo & Educação & 1 \\
\hline Educação: Teoria e Prática (Unesp Rio Claro) & Educação & 1 \\
\hline Em Questão (UFRS) & Administração & 3 \\
\hline Estudios Pedagógicos (Chile) & Educação & 1 \\
\hline ETD: Educação Temática Digital (Unicamp) & Educação & 2 \\
\hline HOLOS (IFRN) & Administração & 4 \\
\hline $\begin{array}{l}\text { Interface: Comunicação Saúde Educação } \\
\text { (UNESP) Scielo }\end{array}$ & Educação & 4 \\
\hline Multi-Science Journal (Instituto Federal Goiano) & Educação & 1 \\
\hline Pro-Posições (SCIELO Unicamp) & Educação & 1 \\
\hline $\begin{array}{l}\text { RAC: Revista de Administração Contemporânea } \\
\text { (ANPAD) }\end{array}$ & Administração & 3 \\
\hline REGE - Revista de Gestão (USP) & Administração & 1 \\
\hline Revista Brasileira de Educação (Anpad) Scielo & Educação & 1 \\
\hline Revista de Administração Mackenzie & Administração & 1 \\
\hline Revista de Administração Pública-RAP (FGV) & Administração & 2 \\
\hline Revista de Ciências da Administração (UFSC) & Administração & 2 \\
\hline Revista de Gestão USP & Administração & 1 \\
\hline Revista Educação Por Escrito & Educação & 1 \\
\hline Revista Iberoamericana de Educación & Educação & 1 \\
\hline $\begin{array}{l}\text { Revista Ibero-Americana de Estudos em } \\
\text { Educação (Unesp) }\end{array}$ & Educação & 1 \\
\hline $\begin{array}{l}\text { RIED: Revista iberoamericana de educación a } \\
\text { distancia }\end{array}$ & Educação & 1 \\
\hline TOTAL & - & 40 \\
\hline
\end{tabular}

Fonte: Elaborado pelos autores (2019). 


\section{Análise dos Resultados}

A análise foi feita tendo como referência a apreciação de cada artigo em sua totalidade, com mais atenção aos itens referencial teórico, problema e tipo de pesquisa, resultados e conclusão.

Os artigos foram separados por abordarem os assuntos de acordo com as categorias. As categorias foram selecionadas por serem as mais citadas e tratadas e os percentuais estão representadas na Tabela 2.

Tabela 2. Categorias de análise

\begin{tabular}{l|c}
\hline \multicolumn{1}{c|}{ Categoria } & \% \\
\hline Práticas pedagógicas & 32 \\
\hline Recursos tecnológicos & 28 \\
\hline Formação de docentes e tutores & 25 \\
\hline Estratégias de aprendizagem & 15 \\
\hline
\end{tabular}

Fonte: Elaborado pelos autores (2019).

\section{Práticas pedagógicas}

Para que as práticas pedagógicas acompanhem as transformações sociais, os educadores precisam estar inseridos em um ambiente que valorize e busque a inovação, mesmo contando com programas de inclusão digital promovidos pelo Governo e por organizações imbuídas dessa missão, é a concepção educacional que o docente e as Instituições de Ensino possuem que influi, diretamente, na melhoria da qualidade de ensino e em uma melhor interação e comprometimento dos jovens estudantes brasileiros.

Destaca-se a importância da presença ativa dos docentes na tomada de decisões didático-pedagógicas juntamente com seus gestores diretos e indiretos, pois são os que mais conhecem a realidade da Instituição de Ensino Superior - IES e o contexto educacional, no qual seus estudantes estão inseridos. Quanto maior a troca 
de experiências entre os sujeitos da ação pedagógica, melhores as chances de se obter resultados construtivos.

Outro aspecto desafiador enfrentado no contexto educacional é a dificuldade, ainda existente, na adoção de metodologias essencialmente ativas, no universo digital, que visem o rompimento de práticas pedagógicas conservadoras, recorrentes e acríticas.

As competências que os estudantes devem alcançar em sua aprendizagem podem ser melhoradas ou facilitadas por meio de métodos pedagógicos, que utilizam novas Tecnologias da Informação e Comunicação - TICs. No entanto, quando se pretende utilizar qualquer tecnologia no processo de ensino e aprendizagem, o docente deve ter em conta a sua integração em uma perspectiva pedagógica para que esse uso seja o mais adequado possível. Um dos fatores primordiais para o processo de Práticas Pedagógicas é a organização das informações buscadas pelos estudantes, em que o docente precisa criar formas de questionamentos para estimular o raciocínio lógico dos estudantes e, dessa forma, provocar um melhor nível de compreensão da tarefa exigida. Segundo Frantz et al. (2018), fica evidente que o objetivo é evidenciar uma experiência com o uso de metodologias ativas, mediadas pelas Tecnologias Digitais - TDs, que evidenciou a experiência com o uso de metodologias ativas, em um ensino híbrido com a utilização do recurso tecnológico da plataforma Moodle.

As mudanças na sociedade trouxeram indagação na esfera educacional quanto ao modelo de práticas docentes empregadas e a finalidade das mesmas na metodologia de ensino. Notou-se que, mesmo diante dos avanços, os métodos, em sala de aula, não correspondiam a uma aprendizagem dinâmica e polivalente com ênfase na formação útil para a vida social. Assim, um caminho possível é a revisão das propostas pedagógicas, o que não significa uma receita sobre como ensinar, mas formam orientações que facilitam a tarefa dos docentes do Ensino Superior nas atividades de ensino, ajudando o docente a produzir conhecimento de técnicas diferenciadas diante das situações diversas. 
Dessa forma, destaca-se a importância de se buscarem instrumentos empíricos para poder fundamentar a prática, compreendendo que a melhora de qualquer situação humana se deve ao conhecimento e ao controle das circunstâncias existentes. Assim, se espera que os docentes possam, com sua prática, enriquecer e ampliar essas sugestões. Portanto, a ação docente deve ter como objetivo a aprendizagem do estudante, desde o conhecimento até a obtenção de valores e atitudes, como confirmado por Santo (2016), os princípios que deveriam nortear a prática de mediação tutorial na Educação a Distância - EaD se relacionam com o estabelecimento do vínculo afetivo-pedagógico com o estudante; a diversificação da prática tutorial; a pronta devolutiva às demandas dos estudantes; o acompanhamento das atividades dos estudantes e a participação regular do tutor em programas de educação continuada na temática da Educação.

Pode-se assumir, dessa maneira, que o uso das metodologias ativas é uma oportunidade de recurso didático para uma formação crítica e reflexiva do estudante universitário, e se lança como uma prática pedagógica inovadora, trazendo a participação coletiva como requisito fundamental para uma aprendizagem expressiva, que objetiva por meio da reflexão, e do compartilhamento de conhecimento, uma formação do estudante como um ser que se forma à medida que se relaciona e se apreende da realidade humana.

Pelo uso dessas metodologias ativas, associadas às práticas cada vez mais reflexivas, críticas e grande comprometimento, é possível aproximar-se de um modelo de ensino que promova a autonomia, a liberdade, o diálogo e o enfrentamento de resistências e de conflitos provenientes do Ensino Superior. Isso pode ser constatado ao se apresentar técnicas metodológicas ativas.

A questão fundamental do ensino híbrido está na lógica de complementar os conteúdos presenciais com o uso da tecnologia em ambientes virtuais, sendo que o êxito pedagógico dessa prática dependerá da instituição e dos docentes, que se propuserem a trabalhar com esta modalidade. 


\section{Recursos tecnológicos}

O uso de tecnologias digitais, no contexto educacional, propicia diferentes possibilidades para as atividades acadêmicas mais significativas para os seus participantes. Assim, percebe-se que a implantação do ensino híbrido pode ser um bom exercício de ampliação de possibilidades para que um maior número de estudantes possa tornar significativo determinado conteúdo.

No que se refere às TIC, as transformações das últimas décadas tiveram seu impacto no ensino e aprendizagem de línguas estrangeiras pela quantidade de recursos disponíveis em sites, aplicativos de celulares ou tablets, canais de televisão e emissoras de rádio online com exercícios, acesso aos dicionários, documentos de áudio, de vídeo e de texto, bem como de jogos lúdicos, quizz culturais, grupos de discussão em redes sociais, hipertextos relacionados a uma ou mais áreas de conhecimento e inúmeros outros recursos que, ao serem integrados às práticas educacionais, possibilitam uma ampliação das formas de ensinar e de aprender. Há, sem dúvida nenhuma, múltiplos espaços de imersão linguística e cultural na língua estrangeira na internet e nas TIC.

Para Abrão e Del Pino (2016), o impacto das novas tecnologias, nas situações didáticas cotidianas, propicia que o sujeito, que domina as novas tecnologias da informação e comunicação, seja alguém que possui imbricado, em si, a cultura de virtualidade construída a partir de um sistema de mídia digital onipresente, interligado e altamente diversificado.

Assim, demanda-se uma remodelação do espaço educacional com enfoque na avaliação diagnóstica, planejamento das atividades e dos grupos, planejamento do espaço de aprendizagem, integração da equipe da IES e a real implementação. Ao transformar a sala de aula em um ambiente de ensino híbrido, no qual celulares e outros dispositivos tecnológicos não sejam proibidos, mas bem-vindos, em que os estudantes não passem horas sentados ouvindo os docentes, e passem a se movimentar pela sala de forma dinâmica, trabalhando em conjunto, o docente poderá dar o passo inicial para 
deixar a massificação do ensino de lado, partindo para um caminho rumo à personalização do ensino (BACICH; MORAN, 2018).

Portanto, as Instituições de Ensino necessitam se conscientizar de que o uso da tecnologia digital pode melhorar o desempenho, aproximar docentes, estudantes e gestores, valorizando o tempo, levando a melhores estratégias de ensino e de aprendizagem.

Dentro do ambiente educacional, as tecnologias são consideradas pelos estudantes e por muitos docentes como uma forma de se evadir de sala de aula, porém se sabe que este conceito está equivocado e que tudo isso deve ser visto como um atrativo a mais que auxilia para uma melhor maneira de conhecimento, ou seja, uma ferramenta de auxílio à prática pedagógica.

As ferramentas tecnológicas devem ser empregadas como suplemento de construção de conhecimento, que vai contribuir no pensamento, na reflexão, na melhora do aprendizado. Segundo Vergara, Hinz e Lopes (2018), sobre a experiência do uso do modelo Laboratório Rotacional com estratégias e práticas pedagógicas que devem ser abordadas para o ensino híbrido, de modo a promover a aprendizagem significativa utilizando a pesquisa exploratória e descritiva, se tem que os resultados obtidos apontam que as aulas com apoio das tecnologias digitais, em que atualmente os estudantes estão imersos, oferecem aos docentes uma nova forma de ensinar e aos estudantes uma nova forma de aprender, através da utilização da metodologia do ensino híbrido.

É necessário que docentes e estudantes entendam a organização do conhecimento em convivência com as tecnologias ofertadas, em que o conhecimento ou a aprendizagem traz um sentido de proximidade constante do conhecimento da realidade atual, que finda oferecendo maiores e melhores adaptações às mudanças culturais e sociais.

Essa transformação da sociedade repercute diretamente na educação, nas IES e no trabalho dos docentes; assim, não é só o docente que precisa de capacitação, a IES como um todo precisa estar preparada com objetivo de caminhar na mesma velocidade que essas transformações acontecem. 
Docentes necessitam se aprimorar, além de estarem preparados para utilizarem as ferramentas tecnológicas, o ensino e a aprendizagem não podem mais fazer a separação entre um e outro, pois estão interligados. E é nesse sentido que é importante o docente empregar as ferramentas disponíveis, com o objetivo de organizar, de planejar e de exibir ao estudante uma nova maneira de aprender, conforme tendência apontada por Reis e Mendes (2018).

Para que estas tecnologias estejam ao alcance dos docentes e dos estudantes é preciso de infraestrutura institucional da IES, para que o trabalho do docente, em se capacitar e acompanhar a evolução tecnológica, através de métodos pedagógicos para que esse aprendizado efetivamente alcance o estudante de forma ampla e completa.

Caso tal panorama seja ignorado, pode ocorrer o que Silva, Silva e Sales (2018) apontaram, em que o objetivo foi aplicar uma metodologia progressista, que integra ensino presencial e remoto, denominada ensino híbrido, e investigar qual a percepção dos estudantes sobre essa metodologia, e o resultado foi, na opinião da maioria dos estudantes, que o uso da tecnologia - ambiente virtual de aprendizagem - AVA - não é necessário para melhorar a compreensão dos conteúdos.

O docente, por meio de recursos tecnológicos, pode estimular práticas que exijam do estudante o raciocínio e que possam resultar no aprender. No entanto, os estudantes não aprendem simplesmente com a tecnologia, mas do pensar sobre o que fazem. Assim, o estudante aprende porque reflete sobre o que fez ou faz, sobre aquilo em que acredita, sobre o que outros fizeram, sobre o próprio processo de reflexão. Diferentes práticas engajam diferentes tipos de pensar. Essas práticas podem ser apresentadas pelo docente ou pela tecnologia, entretanto, nem o docente nem a tecnologia causam o pensar, o aprender.

A articulação dessa reflexão para a construção do conhecimento é fundamental para o uso de sistemas de aprendizagem baseados na tecnologia, que pretendam realmente contribuir para o desenvolvimento do indivíduo, porque lhe permite avaliar as decisões que toma, as estratégias que usa e as respostas que encontra. 


\section{Formação de docentes e tutores}

O desafio do docente em lidar com as tensões entre identidade profissional e reforma pedagógica é uma questão complicada, principalmente, ao considerar a falta da formação específica em docência pelo que passam a maioria dos docentes do Ensino Superior.

Biggs (2012) contribui com a discussão, ao alertar que muitos docentes veem grandes dificuldades em manter os padrões acadêmicos em turmas maiores e mais diversificadas. Para estes problemas, não há solução padronizada, entretanto, existem meios para auxiliar o docente a definir seu papel e exercer com maior assertividade as funções de educador.

O docente terá a missão de inspirar, de desenvolver as necessárias habilidades desses estudantes e, sobretudo, de orientar suas ações, para que possam elaborar e gerir projetos inovadores de alto impacto social e ambiental, para que reconheçam seus espaços neste novo mundo do trabalho, que se insiram adequadamente nas novas posições profissionais, e que sejam agentes transformadores da sociedade, em prol da qualidade de vida.

Segundo Fagundes (2005), é fundamental que a capacitação ofereça ao docente experiências de aprendizagem com as mesmas características que ele terá de proporcionar aos estudantes, cidadãos da sociedade conectada. Portanto, na visibilidade social de um ensino articulado com movimentos sociais contemporâneos, os processos pedagógicos sofrem constantes influências, tornando assim uma mistura de práticas, presenciais e remotas, que podem ser claramente aplicadas em plataformas digitais, que permitam aos estudantes e docentes dialogarem na mesma sintonia, catalisando assim novas formas de construção de um conhecimento real, promissor e atualizado.

Para Cerutti e Melo (2017), que buscaram encontrar o preparo do docente no ensino híbrido como fonte de práticas interativas no Ensino Superior. Se é inadiável preparar o docente para uma prática reflexiva, bem como para a inovação e interação, os dados do estudo indicaram como resultado que é de grande importância que o 
docente esteja preparado para ter e utilizar as tecnologias como parceiras no processo de aprendizagem, bem como tenha capacidade crítica e conhecimento para enfrentar as contradições, as inconsistências e os perigos implícitos que as tecnologias apresentam.

Alves (2014, p.2) defende que o maior problema que o ensino enfrenta hoje é que os docentes são imigrantes digitais que usam uma linguagem da era "pré-digital", e estão lutando para ensinar estudantes, que falam uma linguagem totalmente nova. Ainda, nesse contexto, Lage e Dias (2011, p.7) argumentam que "as pessoas passaram a utilizar a Web de forma natural, pois foram alfabetizadas digitalmente". Oesterreich e Montoli (2012) concluíram que os docentes precisam aprender a dominar os recursos tecnológicos para assim possibilitar uma maior interação com os estudantes, no ambiente virtual de aprendizagem, isto mostra a realidade atual, em que muitos docentes e tutores não foram preparados para atuar dentro de um universo de ensino, utilizando tecnologias digitais.

Outro aspecto importante sobre a preparação dos docentes tem relação com as condições de trabalho: Saviani (2009) defende que a questão da formação dos docentes não pode ser dissociada do problema das condições de trabalho, que envolvem a carreira docente, em cujo âmbito devem ser equacionadas as questões da remuneração e jornada de trabalho. Com efeito, as condições precárias de trabalho não apenas neutralizam a ação dos docentes, mesmo que fossem bem formados. Tais condições dificultam também uma boa formação, pois operam como fator de desestímulo à procura pelos cursos de formação docente e à dedicação aos estudos.

É preciso acabar com a duplicidade pela qual, ao mesmo tempo em que se proclamam as virtudes do ensino, exaltando sua importância decisiva na sociedade, denominada como "sociedade do conhecimento", as políticas predominantes se pautam pela busca da redução de custos, extirpando os investimentos.

Mateus (2014) indica que políticas, verdadeiramente, comprometidas com a qualidade da formação dos docentes precisam ir muito além de estratégias de reorganização da relação entre as 
Instituições de Ensino para abraçar a responsabilidade com as dimensões sociais da profissionalização docente, oportunizando um trabalho digno.

Diante do que foi analisado se conclui que a construção do conhecimento no Ensino Superior ocorre, especialmente, nas relações e contato do docente com o estudante, e na forma que o docente trabalha com o conceito de ensino e aprendizagem, instigando o estudante a não apenas decorar, mas a ser um sujeito que pensa, que tenha prazer em aprender, que saiba compreender informações, e que enxergue nas dúvidas uma oportunidade de aprendizagem.

Inovação, mudança e prazer pelo novo deve ser frequente na aula, pois uma das características marcantes da modernidade é o inovar sempre. O docente do Ensino Superior é parte fundamental na construção do aprendizado, e tem que ter certeza de que sua formação não está terminada, exigindo aprimoramentos, produções e um aprendizado constante.

A aprendizagem do estudante universitário ocorre quando há mudanças efetivas em seu comportamento: ele terá a certeza de que construiu, descobriu e acrescentou alguma coisa em sua forma de pensar. E, para que isto ocorra, é preciso uma direção no ensino voltada para o questionamento. $\mathrm{O}$ estudante busca significados, restaura o conhecimento aprendido em aula e as informações que foram transmitidas.

Reconhecimento docente, progressão de carreira e remuneração digna deve ser praticada pelas IES, os docentes terão que se manter atualizados, as IES deverão valorizar seu corpo docente, o maior recurso que uma IES tem não é apenas sua infraestrutura ou marca, também seus funcionários e, principalmente, seus docentes.

\section{Estratégias de aprendizagem}

As estratégias de aprendizagem são passíveis de serem aprendidas e, portanto, modificadas. Assim, o ensino e aperfeiçoamento de tais estratégias implicariam, não necessariamente, na mudança dos procedimentos instrucionais, mas afetariam a maneira 
que os aprendizes procedem ao aprender, podendo melhorar seu aproveitamento durante o aprendizado. O estudo das estratégias de aprendizagem pode orientar o planejamento instrucional de um curso e auxiliar no entendimento dos processos de aprendizagem individuais envolvidos (SANTOS; et al., 2004; ZERBINI, 2007).

Essa conjuntura diz respeito à relação do docente no processo de ensinar e produzir conhecimento, pois as forças e compromissos, que atuam sobre o docente em cada período materializam sua identidade docente e retratam um definido momento da cultura escolar. Uma relação muitas vezes mediada pela dualidade entre manter a tradição e o poder do educar, ou dividir o protagonismo do processo de aprendizagem com os estudantes, na busca da edificação participativa do conhecimento.

Identificar e debater dificuldades encontradas no Ensino Superior para propor um processo metodológico que possa colaborar com o melhor rendimento. Para Moura, Tassigny e Silva (2018), a combinação de aprendizagens individuais e em grupo, com o uso da tecnologia, entre estudantes e mediada por docentes mais experientes se traduz na melhor e mais efetiva forma de aprendizagem, nos tempos contemporâneos.

Utilizando-se o ensino híbrido é possível ao docente permitir que o estudante se torne mais autônomo, participativo e protagonista do seu aprendizado, ampliando o seu pensamento crítico, a fim de correlacionar o que está em estudo com as situações da vida real.

Observa-se, nos artigos analisados neste trabalho, um grupo de questões sobre avaliação e aprendizagem no Ensino Superior. Tendo por base alguns estudos que agregam avaliação e aprendizagem, percebe-se que as práticas de avaliação realizadas pelos docentes apresentam diversas consequências sobre as atitudes de aprendizagem mostradas pelos estudantes.

As escolhas feitas pelos docentes podem aumentar ou restringir as oportunidades para que os estudantes declarem o que aprenderam. Tais aspectos são fundamentais, atualmente, considerando a importância que as práticas de avaliação formativa vêm 
conquistando. Essa escolha precisa levar em conta tanto o tipo de aprendizagem que os docentes querem adotar quanto as possíveis respostas dos estudantes.

Segundo Siqueira e Torres (2010), foi possível detectar depoimentos positivos dos estudantes quanto à realização das atividades presenciais mediadas pelas plataformas digitais, ratificando a proposta de ensino híbrido como uma alternativa metodológica para os docentes. Ressalta-se, assim, a importância de os docentes refletirem sobre suas práticas, considerando a profunda atuação que estas exercem sobre a aprendizagem dos estudantes.

Tanto a educação presencial como a remota caminham para modelos diferentes dos que se está habituado. O presencial se flexibiliza com o remoto e aumenta a utilização de ambientes de aprendizagem com atividades de discussão individuais e em grupo - fóruns. A educação remota, à medida que a sociedade se conecta mais, utiliza mais os mesmos ambientes virtuais para acesso à informação e para compartilhamento de discussões e experiências.

A aprendizagem remota é uma constante no dia a dia, no trabalho, em casa, na vida. A educação tradicional necessita incorporar muito mais profundamente todas as possibilidades destes novos ambientes, principalmente, focando o estudante e a participação como eixos de uma educação ativa e transformadora. É possível combinar, quando necessário, vídeo-aulas e atividades colaborativas em grupos, que construam situações vivas de aprendizagem compartilhadas.

Pode-se aproveitar o melhor do modelo de transmissão com as vantagens do modelo de colaboração. É possível avançar muito mais na integração dos modelos focados na transmissão, no conteúdo e no docente com os modelos colaborativos de efetiva pesquisa, colaboração e compartilhamento. Têm-se inúmeras possibilidades de aprendizagem, que podem combinar o melhor do presencial, quando possível, com as vantagens do remoto.

O futuro indica cidades inteligentes, conectadas, o acesso podendo ser feito instantaneamente de qualquer lugar e a qualquer 
hora e com equipamentos acessíveis. Quanto mais acesso, mais necessidade de mediação, de pessoas que inspirem confiança e que sejam competentes para auxiliar os estudantes a encontrarem os melhores conteúdos, os melhores autores e saber compreendê-los e incorporá-los à realidade.

\section{Considerações Finais}

O cenário descrito sugere que as IES devem dar oportunidade para que seus docentes para ofereçam ambientes de experiências de ensino híbrido, que proporcionem aos estudantes descobrirem que a utilização do ambiente virtual de aprendizagem deve ser utilizada para o aprendizado, certamente, o debate sobre os recursos tecnológicos é fundamental e muito mais difícil do que se imagina. Muitas vezes se espera que a tecnologia seja parte integrante de um projeto pedagógico contemporâneo, todavia, o que pode ser transformador para o docente, para o estudante pode não ser.

Seguindo esta suposição, é importante que o docente esteja preparado para deter e utilizar os recursos tecnológicos como aliado no processo de aprendizagem, sendo preciso também que o docente tenha conhecimento crítico e capacidade para encarar as controvérsias, incoerências e os riscos que estas tecnologias contêm.

Para que esse panorama se contemple, é fundamental que, além do docente, a IES altere sua metodologia, providencie inovação e adaptação para as possibilidades tecnológicas, que estão disponíveis e que podem ser utilizadas no processo de aprendizagem. Assim, a relação com o ambiente virtual de aprendizagem encorajará o estudante a buscar e explorar o conteúdo disponível e, assim, de forma motivadora e interativa aumentar seu conhecimento.

As possibilidades didáticas com o ensino híbrido recomendarão aulas que o estudante, habituado ao uso de tecnologias, possa utilizar a favor de sua construção, entendendo a definição de sua autonomia e protagonismo, mais uma vez, o ponto do raciocínio está no docente como questionador de processos com atividades provocadoras aos estudantes para que eles pratiquem sua criatividade e amplifiquem habilidades e competências diferentes. 
Com base nos quarenta artigos analisados se pode considerar que o ensino híbrido tem se configurado em sensível tendência pedagógica, a partir da expansão das TICs. Esta categoria de ensino se mostra como um novo atributo para responder, principalmente, os estudantes de uma geração mais nova, que não se satisfazem, exclusivamente, com a sala de aula tradicional. A grande quantidade e variedade dos recursos tecnológicos que os estudantes têm acesso, para a maioria deles aceitar uma aula no modelo tradicional é um grande desafio.

Estes recursos permitem a personalização da aprendizagem e a avaliação passa a ser uma ferramenta para a realização dos propósitos educacionais, ajudando no método de aprendizagem do estudante e não unicamente para aprovação no componente curricular.

O modelo de ensino híbrido conduz aos desejos dos estudantes, pois é factível na liberdade do estudo remoto, por meio dos recursos tecnológicos que são oferecidos pelas IES, ou esses conhecimentos podem ser empregados em aulas presenciais com o contato face a face com os outros estudantes e com o intermédio do docente. É esperado que com o modelo de ensino híbrido, tanto os estudantes quanto os docentes, formem um novo espaço de aprendizagem.

É importante que os sujeitos do processo educacional procurem melhorias e aprimoramento à frente das carências provenientes deste contexto. No decorrer da história da humanidade, o ponto de vista do homem e de suas necessidades resultou em mudanças socioculturais. Com o surgimento das tecnologias, a expansão e os avanços, novas tecnologias influenciam a vida das pessoas.

Estudantes, docentes, familiares e outros introduzidos no método de organização do ensino devem assimilar o conceito destas novas tecnologias em benefício do ensino. Sabe-se que é muito assertivo, no ensino híbrido, o fato de as TICs serem ligadas à composição didática. Entretanto, não se pode pensar que é somente inserir as novas tecnologias nas IES que as questões do ensino serão solucionadas, especialmente, as elencadas no processo de ensino e aprendizagem. 
Dessa maneira, é considerável evidenciar que, na leitura dos artigos, um dos fundamentos apresentados como contributo teórico é a utilização das TICs, tendo o modelo de ensino híbrido como um dos elementos que determinam as técnicas a serem utilizadas na metodologia de ensino e aprendizagem. Isto posto sobre as TICs, uma forma de entender que suas repercussões representam as práticas educativas nas aulas.

Todavia, compete interpretar que ao se oferecer estas tecnologias não significa que, ao utilizá-las em salas ou em ambientes virtuais de aprendizagem, surgirão novas práticas de ensino híbrido. As TICs são instrumentos integrados na metodologia ativa do ensino híbrido, sendo necessário uma disposição, assim como outras ferramentas introduzidas nesta metodologia.

É significativo entender que estes procedimentos abrem caminho para a transformação no aprendizado e possibilitam, tanto ao docente quanto ao estudante, aperfeiçoamento e melhorias, em sala de aula, utilizando todas as tecnologias disponíveis, porque essas robustecem as práticas pedagógicas no modelo presencial ou remoto. Estas provocações são pertinentes aos conceitos, competências e habilidades manifestados pelos estudantes, docentes e gestores.

Esta alegação se reforça à medida que se compreende que tais modificações serão implementadas como mais um artifício em prol do ensino e não serão extintas as outras metodologias. Compreender os princípios do ensino híbrido propiciou perceber que não se exauriu o debater, principalmente, pelos meios das políticas públicas, os direcionamentos que se têm ainda não são suficientes para a realização de práticas, pois demandam investimentos financeiros, de infraestrutura, de recursos e de formação continuada.

As insuficiências que envolvem são muito grandes e requerem mais estudos. Dessa forma, pode-se fundamentar a quantidade de artigos encontrados para este estudo, sendo importante fortalecer os estudos referentes ao ensino híbrido, além de aprimorar o conhecimento e compreensão e dar continuidade, ou seja, provocar 
os pesquisadores e a academia a debaterem sobre a importância das políticas públicas na efetivação do ensino híbrido.

Uma das dificuldades encontradas está relacionada às publicações, visto que ainda há muito que evoluir nesse assunto, e isto se deve ao fato que instituir, no âmbito das IES, novas práticas de ensino pressupõem mudanças, o que necessita medidas objetivas nas práticas pedagógicas.

É impossível propiciar inovações no processo de ensino sem recursos financeiros, sem planejamento, sem ferramentas adequadas, sem direcionamentos muito bem estabelecidos e extensivamente debatidos com todos os setores abrangentes, pois com a efetivação, as mudanças serão indispensáveis, e apesar da propensão do uso das tecnologias, em distintos segmentos sociais, na educação, esta metodologia demanda reformulação.

Após o estudo, observando as categorias para análise, esses são propícios sob o ponto de vistas do docente, do tutor, do estudante e de todos os envolvidos nessa metodologia. Concretizar o ensino híbrido é muito diferente de somente discuti-lo.

Retomando o objetivo deste estudo de apresentar as características das práticas do ensino híbrido em IES, no Brasil, expostos nos artigos selecionados, conclui-se que apesar dos artigos demostrarem no título e também no resumo indicações de inferências teóricas referente ao ensino híbrido, o conteúdo do texto poderia ser mais bem explorado.

Verifica-se que os artigos apresentam informações que são favoráveis ao uso de novas tecnologias no processo educacional, e os autores, em sua totalidade, salientam que a aprendizagem é mais significativa quando os estudantes se apropriam destas ferramentas. Com a inserção do ensino híbrido, o estudante tem um controle maior no processo de aprendizagem, estabelecendo períodos para estudar de acordo com seu ritmo, utilizando as tecnologias e o ambiente virtual de aprendizagem, o estudante pode assistir as vídeo-aulas quantas vezes forem necessárias. Percebe-se que é possível implantar o ensino híbrido e se destaca a capacitação como parte importante para o sucesso desta modalidade. 
Portanto, ressalta-se a relevância deste estudo para a academia, o estudo sobre o ensino híbrido precisa ser mais investigado por sua contribuição na área da Educação. A capacitação e o aperfeiçoamento dos docentes e tutores são caminhos para se descobrirem novas formas de aplicação na metodologia de ensino. É necessário que se tenha compreensão sobre as discussões na formação docente, sobre as necessidades de mudanças na rotina de trabalho, na organização, na competência e nas vertentes pessoais.

Para futuros estudos se recomenda que se procure entender a compreensão dos docentes e tutores referentes à utilização de metodologias ativas no Ensino Superior e quais as dificuldades para sua inserção, considerando que são necessárias mudanças no processo de ensino e aprendizagem.

Sugere-se, também, estudos no campo da educomunicação para procurar pensar, pesquisar, trabalhar a educação formal, informal e não formal dentro do conjunto comunicativo.

Recomenda-se para novos estudos a utilização dos canais de mídia para disseminação de informações para o aprendizado, como exemplo: Redes Sociais, Blogs, YouTube etc. Assim, ter-se-á um conjunto de estudos, cujos resultados podem contribuir para avanço na discussão sobre o tema do ensino híbrido.

\section{Referências}

ABRÃO, K. R.; DEL PINO, J. C. Cognição e aprendizagem no espaço da tecnologia. Revista Ibero-Americana de Estudos em Educação, v. 11, n. 4, p.17761798, 2016.

AL-ALWANI, A. Information technology integration in higher education: A novel approach for impact assessment. International Journal of Emerging Technologies in Learning, v. 9, n. 6, p. 32-36, 2014.

ALVES, E. J. Literacia Digital de Professores: competências e habilidades para o uso das TDIC na docência. Didática e Prática de Ensino na relação com a Escola. EdUECE, 2014.

BACICH, L.; MORAN, J. M. Metodologias ativas para uma educação inovadora: uma abordagem teórico-prática. Porto Alegre: Penso, 2018. 
BACICH, L.; TANZI NETO, A.; TREVISANI, F. de M. (Org.). Ensino híbrido: personalização e tecnologia na educação. Porto Alegre: Penso, 2015.

BIGGS, J. What the student does: teaching for enhanced learning. Higher Education Research and Development, v. 31, n. 1, p. 39-55, 2012.

CALIPO, V. Mídias digitais sociais no auxílio ao EAD: As Novas Tecnologias da Informação e da Comunicação como processo facilitador na relação de ensino-aprendizagem. Tese (doutorado em Comunicação Social). Universidade Metodista de São Paulo, 2013.

CERUTTI, E.; MELO, L. F. Abordagem híbrida no Ensino Superior: reflexões teórico-metodológicas. Revista On-Line de Política e Gestão Educacional, v. 21, n. esp. 1, p. 605-620, out. 2017.

CHAN, W.; LEUNG, C. H. The Use of Social Media for Blended Learning In Tertiary Education. Universal Journal of Educational Research, v. 4, n. 4, p. 771-778, 2016.

CHRISTENSEN, C.; HORN, M.; STAKER, H. Ensino Híbrido: uma Inovação Disruptiva? Uma introdução à teoria dos híbridos. Editora Porvir, 2013.

CRUZ, J. A. S.; BIZELLI, J. L. Sociedade, tecnologias e educação: as tecnologias da informação e comunicação e o pensar da sociedade concreta. Cadernos de Educação, Tecnologia e Sociedade, v. 1, n. 5, p. 258-266, 2014.

FAGUNDES, L. C. Entrevista com Léa Fagundes sobre a inclusão digital. Revista Nova Escola, São Paulo, 2005.

FERREIRA, R. C. A.; VIEIRA, A. M. Trabalho docente e tecnologias da educação: mediação e confluência. Revista de Tecnologia Aplicada, v. 2, n. 3, p. 46-62, 2013.

FIORAVANZO, C. M.; VIEIRA, A. M.; CLARO, J. A. C. S. Avaliação e devolutiva: elementos indissociáveis no contexto do ensino superior a distância. Holos, v. 1, p. 107-123, 2016.

FRANTZ, D. S. F.; S.; NUNES, J. F.; MARQUES, I. L.; MARQUES, N. L. R. Ensino híbrido com a utilização da plataforma Moodle. Revista Thema, v. 15, n. 3, p. 1175-1186, 2018.

GABRIEL, M. Educ@r - a (r)evolução digital na educação. São Paulo: Saraiva, 2013. 
GADOTTI, M. História das ideias pedagógicas. São Paulo: Ática, 1999.

GÜZER, B., CANER, H. The Past, Present and Future of Blended Learning: An in Depth Analysis of Literature. Procedia Social and Behavioral Sciences, v. 116, p. 4596-4603, 2014.

HORN, M. B.; STAKER, H. Blended: usando a inovação disruptiva para aprimorar a educação. Porto Alegre: Penso, 2015.

JARAUTA, B.; IMBERNON, F. Pensando no futuro da educação: uma nova escola para o século XXII. Porto Alegre: Penso, 2015.

JOHNSON, L.; BECKER, S.; CUMMINS, M.; ESTRADA, V. NMC Technology Outlook for Australian Tertiary Education: A Horizon Project Regional Report, 2014.

LAGE, M. O.; DIAS, A. M. Literacia Informacional e mediática no mundo digital e em contexto de ensino profissional: novo mito ou plano necessário de acção? Congresso Nacional de Bibliotecários, Arquivistas e Documentalistas, Portugal. Anais..., 2011.

MATEUS, E. F. Um esboço crítico sobre "parceria" na formação de professors. Educação em Revista, v. 30, n. 03, p. 355-384, Julho-Setembro, 2014.

MEANS, B.; TOYAMA, Y.; MURPHY, R.; BAKIA, M. The Effectiveness of On-line and Blended Learning: A Meta-Analysis of the Empirical Literature. Teachers College Record, v. 115, n. 3, p. 1-47, 2013.

MENDONÇA NETO, O. R.; VIEIRA, A. M.; ANTUNES, M. T. P. Industrialização da Educação, Edtech e Prática Docente. EccoS - Revista Científica, v. 47, p. 149-170, 2018.

MORAN, E. Ensino híbrido: personalização e tecnologia na educação. In: BACICH, L.; TANZI NETO, A.; TREVISANI, F. M. Ensino Híbrido: Personalização e tecnologia na educação. Porto Alegre: Penso, 2015.

MORAN, J. M.; MASETTO, M.; BEHRENS, M. Novas Tecnologias e Mediação Pedagógica. São Paulo: Papirus, 2007.

NAZARENKO, A. Blended Learning vs Traditional Learning: What Works? (A Case Study Research). Procedia-Social and Behavioral Sciences, v. 200, p. 77 82, 2015. 
OESTERREICH, F.; MONTOLI, F. S. Blended learning como uma proposta metodológica adotada no ensino superior. Anais... IX Encontro Virtual de Documentação em Software Livre e VI Congresso Internacional de Linguagem e Tecnologia online v. 1, n. 1, 2012.

PEERAER, J.; VAN PETEGEM, P. Integration or transformation? Looking in the future of Information and Communication Technology in education in Vietnam. Evaluation and Program Planning, v. 48, p. 47-56, 2015.

PEREIRA, C. S. T.; VIEIRA, A. M.; DAMIÃO, W. S. Dimensões da Inovação na Pós-Graduação: Papéis e Significados. Revista Organizações em Contexto, v. 14, n. 27, p. 211-234, 2018.

RAZEP, E.; ABEL, U. Acceptance factors and current level of use of Web 2.0 technologies for learning in higher education: A case study of two countries. International Journal of Advanced Computer Science and Applications, v. 5, n. 5 , p. 9-14, 2014.

REIS, V.; MENDES, G. M. L. De iniciantes a vanguardistas: o uso de tecnologias digitais por jovens professores. Holos, v. 1, p. 297-316, 2018.

RIDEOUT, V. J.; FOEHR, U. G.; ROBERTS, D. F. Generation M [superscript 2]: Media in the Lives of 8 to 18 Year-Olds. Henry J. Kaiser Family Foundation, 2010 .

ROMANOWSKI, J. P.; ENS, R. T. As pesquisas denominadas do tipo "estado da arte” em educação. Revista Diálogo Educacional, v. 6, n. 19, p. 37-50, 2006.

ROMERO, T. Educação sem distância: as tecnologias interativas na redução de distâncias em ensino e aprendizagem. São Paulo: SENAC, 2010.

SANTO, E. E. Ensinar e aprender na Educação a Distância: um estudo exploratório na perspectiva das práticas tutoriais. Research, Society and Development, v. 3, n. 2, p. 92-114, 2016.

SANTOS, A. A. A.; BORUCHOVITCH, E.; PRIMI, R.; ZENORINI, R. P. C.; BUENO, J. M. H. Escala de Avaliação de Estratégias de Aprendizagem para universitários (EAP-U): aplicação do Modelo de Rasch de créditos parciais. Psicologia: Teoria, Investigação e Prática, v. 9, n. 2, p. 227-242. 2004.

SAVIANI, D. Formação de professores: aspectos históricos e teóricos do problema no contexto brasileiro. Revista Brasileira de Educação, Rio de Janeiro, v. 14, n. 40, p. $143-155,2009$. 
SHERRON, G.T.; BOETTCHER, J.V. Distance learning: the shift to interactivity (professional paper series, \#17). Colorado (EUA): Cause/Boulder, 1997.

SILVA, J. B.; SILVA, D. O.; SALES, G. L. Modelo de ensino híbrido: a percepção dos alunos em relação à metodologia progressista $\mathrm{x}$ metodologia tradicional. Revista Conhecimento Online, a. 10 v. 2, 2018.

SIQUEIRA, L. M.; TORRES, P. L. O ensino híbrido da eletricidade utilizando objetos de aprendizagem na engenharia. Cad. Bras. Ens. Fís., v. 27, n. 2, p. $334-$ $354,2010$.

TOMACHEVSKI, E.; LEPCHAK, A. O estado da arte da contabilidade gerencial no Brasil: um comparativo com resultados internacionais contemporâneos. Enfoque: Reflexão Contábil, v. 38, n. 1, p. 15-31, 2019.

VERGARA, A. C. E.; HINZ, V. T.; LOPES, J. L. B. Como Significar a Aprendizagem de Matemática Utilizando os Modelos de Ensino Híbrido. Revista Thema, v. 15 , n. 3, p. 885- 904. 2018.

VIEIRA, A. M. Cultura organizacional em instituições de ensino: mapeamento e análise descritivo-interpretativa da produção acadêmica (1990-2005). 2007. 237f. Tese (Doutorado em Educação) - Universidade Estadual Paulista (UNESP), Marília, 2007.

VIEIRA, A. M.; RIVERA, D. P. B. A Hermenêutica no Campo Organizacional: duas possibilidades interpretativistas de pesquisa. Revista Brasileira de Gestão de Negócios, v. 14, n. 44, p. 261-273, 2012. 